\title{
ISLI is upregulated in breast cancer and promotes cell proliferation, invasion, and angiogenesis
}

This article was published in the following Dove Press journal:

OncoTargets and Therapy

\author{
Lin $\mathrm{Li}^{1}$ \\ Fuwen Sun ${ }^{2}$ \\ Xiaoyan Chen ${ }^{3}$ \\ Minghui Zhang' \\ 'Department of Imaging, Linyi People's \\ Hospital of Shandong Province, \\ Linyi, People's Republic of China; \\ ${ }^{2}$ Department of Interventional, \\ Affiliated Hospital of Shandong \\ Medical College, Linyi, People's \\ Republic of China; ${ }^{3}$ Department of \\ Spine Surgery, Linyi People's Hospital \\ of Shandong Province, Linyi, People's \\ Republic of China
}

\begin{abstract}
ISL1 plays a key role in several cancers, including pheochromocytoma, gastrointestinal, pancreatic, and lung tumors and bile duct carcinoma. In order to elucidate the role of ISL1 in breast cancer, we performed quantitative real-time polymerase chain reaction and Western blotting analysis, and we found that ISL1 was upregulated in breast cancer cells and tissues. Moreover, high expression of ISL1 was correlated with tumor size, metastasis, and poor prognosis. Colony formation analysis and CCK-8 analysis revealed that ISL1 facilitated breast cancer cell proliferation. In addition, wound healing analysis and transwell invasion analysis demonstrated that ISL1 played a role in cell migration and invasion. Interestingly, the expression of ISL1 was also associated with the expression of vascular endothelial growth factor (VEGF) in breast cancer, and ISL1 promoted angiogenesis in breast cancer. In conclusion, reducing the expression of ISL1 suppresses proliferation, migration, invasion, and angiogenesis in breast cancer, suggesting that ISL1 might serve as a novel molecular therapy target in breast cancer.
\end{abstract} Keywords: ISL1, proliferation, metastasis, angiogenesis, breast cancer

\section{Introduction}

Breast cancer is a global problem; it has become one of the most common cancers among women in the world. ${ }^{1}$ Treatment of breast cancer is associated with the diagnosis and specific characteristics of the breast carcinoma, including genetic mutations and hormone production. ${ }^{2}$ Although there have been a lot of advances in medicine, early diagnosis and treatment of breast cancer is infrequent, and therefore, breast cancer is usually diagnosed in the advanced stages. ${ }^{3}$

ISL1, also known as Islet-1, is a LIM-homeodomain transcription factor. ${ }^{4}$ ISL1 has been found to play crucial roles in multiple tissue types, such as heart, kidneys, skeletal muscle, nervous system, and endocrine organs. ${ }^{5}$ Moreover, several studies also reveal that ISL1 plays a key role in differentiation, cell specification, and maintenance of phenotypes of the horizontal cells, cholinergic amacrine and ganglion in the retina. ${ }^{6}$ In addition, previous studies have suggested that ISL1 is highly expressed in rhabdomyosarcoma ${ }^{7}$ and gastric cancer, ${ }^{8}$ and associates with advanced tumor stage, tumor size, metastasis, and poorer overall survival. ${ }^{8,9}$ Recently, ISL1 has been reported to promote angiogenesis in human umbilical vein endothelial cells (HUVECs) through regulating the expression of vascular endothelial growth factor (VEGF). ${ }^{10}$ However, the detailed function of ISL1 in breast cancer remains unknown.

Angiogenesis takes part in the pathophysiology of ischemic cardiomyopathy, wound healing, atherosclerosis, stroke, and cancer. Many studies have suggested that the angiogenic factor VEGF is a new molecular treatment for diseases. ${ }^{11}$ In addition, anti-VEGF therapy is a novel treatment of cancer through inhibiting angiogenesis. ${ }^{12}$
Correspondence: Minghui Zhang Department of Imaging, Linyi People's Hospital of Shandong Province, Number 233 Fenghuang Street, Hedong District, Linyi, 276034, People's Republic of China Tel +865398092120

Email kb60tym@163.com

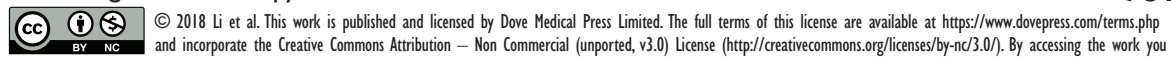
BY NC and incorporate the Creative Commons Attribution - Non Commercial (unported, v3.0) License (http://creativecommons.org/licenses/by-nc/3.0/). By accessing the work you
hereby accept the Terms. Non-commercial uses of the work are permitted without any further permission from Dove Medical Press Limited, provided the work is properly attributed. For permission for commercial use of this work, please see paragraphs 4.2 and 5 of our Terms (https://www.dovepress.com/terms.php). 
To date, the main anti-VEGF antibodies are Macugen, ${ }^{13}$ Lucentis, ${ }^{14}$ and Avastin. ${ }^{15}$

Here, our study indicates that ISL1 is upregulated in breast cancer cell lines and tissue samples. Moreover, a high expression of ISL1 is corrected with tumor size, metastasis, and poor prognosis. Several functional experiments, including colony formation analysis, CCK-8 assay, wound healing assay, and transwell invasion analysis, demonstrate that ISL1 facilitates cell proliferation, migration, and invasion in breast cancer cells. In breast cancer, ISL1 also promotes angiogenesis. Blood vessels can supply nutrition for cancer cells, promoting cancer cell proliferation and metastasis, which might explain the reason why high expression of ISL1 is corrected with tumor size and metastasis.

\section{Materials and methods}

\section{Specimens and ethics statement}

A total of 108 pairs of adjacent normal tissue samples and breast cancer tissue samples were obtained from the Affiliated Hospital of Shandong Medical College from 2010 to 2015. This study was approved by the ethical committee of the Affiliated Hospital of Shandong Medical College. All patients provided written informed consent.

\section{Cell culture}

Human breast cancer cell lines MDA-MB-231 and MCF-7, human normal breast tissue cells MCF-10A, and HUVECs were purchased from the American Type Culture Collection (ATCC, Manassas, VA, USA). MDA-MB-231 and MCF-7 cells were cultured in RPMI 1640 (GIBCO, Gran Island, NY, USA) or Dulbecco's Modified Eagle's Medium (DMEM; GIBCO), respectively, containing 1\% Penicillin-Streptomycin and 10\% fetal bovine serum (FBS; HyClone, Logan, UT, USA) at $37^{\circ} \mathrm{C}$ with $5 \% \mathrm{CO}_{2}$. MCF-10A cells were cultured in the Mammary Epithelial Cell Medium containing Mammary Epithelial Cell Growth Supplement and 1\% PenicillinStreptomycin (Sciencell, Carlsbad, CA, USA). The HUVECs were incubated in Endothelial Cell Medium (ECM; Sciencell) containing 1\% Penicillin-Streptomycin, 1\% Endothelial Cell Growth Supplement (ECGS), and 5\% FBS.

\section{Cell transfection}

Cells were transfected with pCMV-Tag2B (vector) or pCMV-Tag2B-ISL1 using lipo2000 reagent (Thermo Fisher Scientific, Waltham, MA, USA) when cell confluence was $70 \%-80 \%$. For knockdown ISL1, cells were transfected with scramble siRNA (SCR) or ISL1 siRNA (silSL1) using RNAimax reagent (Thermo Fisher Scientific) when cell confluence was 30\%-40\%. After transcription for 48 hours, cells were collected and used for further experiments.

\section{Western blotting}

The tissue sample and cultured cells were lysed using RIPA buffer (Beyotime, Jiangsu, People's Republic of China) containing protease inhibitors and cocktail (Boehringer, Mannheim, Germany). The protein concentration was measured using BCA kit (Thermo Fisher Scientific). A $40 \mu \mathrm{g}$ protein was resolved with a $10 \%$ sodium dodecyl sulfate-polyacrylamide gel (SDS-PAGE), transferred to a polyvinylidene fluoride (PVDF) membrane, and incubated with 5\% skimmed milk at room temperature for 1 hour. The membranes were washed with PBST three times and then incubated with indicated antibodies at $4^{\circ} \mathrm{C}$ overnight. The membranes were washed with PBST three times, followed by incubation with HRP-conjugated secondary antibodies at room temperature for 1 hour. Finally, the enhanced chemiluminescence (ECL) reagent (Thermo Fisher Scientific) was used to detect the specific protein band. All the experiments were repeated at least three times. The antibodies were as follows: ISL1 antibody (1:500, Abcam, Cambridge, MA, USA), VEGF antibody (1:1,000; Abcam), and $\beta$-actin antibody (1:5,000; Sigma, Danvers, MA, USA).

\section{CCK-8 analysis}

CCK-8 analysis was performed to determine the cell proliferation. ISL1 was overexpressed or knocked down in MCF-7 cells; after a transcription of 48 hours, a total of $3 \times 10^{3} \mathrm{MCF}-7$ were placed in 96-well plates. Every 24 hours, each $100 \mu \mathrm{L}$ media was added $10 \mu \mathrm{L}$ CCK-8 reagent (Beyotime, Jiangsu, People's Republic of China) and cells were incubated at $37^{\circ} \mathrm{C}$ for 1 hour. The absorbance of OD $450 \mathrm{~nm}$ each clearly indicated the number of surviving cells. All the experiments were repeated at least three times.

\section{Quantitative real-time polymerase chain reaction CR (qRT-PCR)}

Total RNA of tissue samples and cells were prepared using TRIzol reagent (Thermo Fisher Scientific). M-MLV Reverse Transcriptase kit (TransGen, Beijing, People's Republic of China) was used to synthesize cDNA according to the instructions. Next, SYBR (Roche Diagnostics, Mannheim, Germany) was utilized to perform qRT-PCR. The primers were as follows: ISL1 forward: 5'-TGGACATTACTCCCTCTTACAG-3', reverse: 5'-CCCGTACAACCTGATATAATCTC 775 23-3'; VEGF forward: 5'-GACATCTTCCAGGAGTACCC-3', reverse: 5'-TCTTTCTTTGGTCTGCATTCAC-3; GAPDH 
forward: 5'-ATTTCCTGGTATGACAACGA-3', and reverse: 5'-TTGATGGTACATGACAAGGTG-3'. GAPDH was used as an internal control. All the experiments were repeated at least three times.

\section{Transwell invasion analysis}

The transwell invasion analysis was performed to determine the effect of ISL1 on cell invasion. In brief, each transwell invasion chambers $(8-\mu \mathrm{m}$ pore size; Millipore Corporation, Billerica, MA, USA) was coated with $100 \mu \mathrm{L}$ Matrigel (BD Biosciences, San Diego, CA, USA) according to the manufacturer's protocol. $3 \times 10^{4} \mathrm{MDA}-\mathrm{MB}-231$ cells were resuspended with serum-free DMEM medium and placed on the top of Matrigel-coated chambers; the lower chambers were filled with $600 \mu \mathrm{L}$ DMEM containing 10\% FBS. The cells were incubated at $37^{\circ} \mathrm{C}$ with $5 \% \mathrm{CO}_{2}$ for 24 hours and stained with $0.5 \%$ violet crystal, and then a cotton swab was used to remove the cells that remained on the top of the filter. Finally, the number of invaded cells was counted under a light microscope. All the experiments were repeated at least three times.

\section{In vitro tube formation analysis}

In vitro tube formation analysis was performed using growth factor-reduced Matrigel (BD Biosciences), as previously described. ${ }^{16}$ Briefly, a $200 \mu \mathrm{L}$ growth factor-reduced Matrigel was coated in the 24-well plates and then solidified at $37^{\circ} \mathrm{C}$ for 30 minutes. HUVECs were cultured with $\mathrm{CM}$ from MCF-7 cells that were transfected with vector, ISL1 or SCR, siISL1. After incubation for 24 hours, the number of tubes formed was counted under a light microscope. All the experiments were repeated at least three times.

\section{Statistical analysis}

All experiments were repeated at least three times. All data were analyzed by SPSS 19.0 software (IBM Corp., Armonk, NY, USA) and presented as mean \pm standard deviation (SD). Student's $t$-test was utilized to assess the statistical significance between two groups. The Kaplan-Meier method was used to detect the prognostic significance of ISL1. ${ }^{*} P<0.05$ was considered significant.

\section{Result}

ISLI is upregulated in breast cancer, and the expression of ISLI is corrected with tumor size and metastasis

In order to determine the role of ISL1 in breast cancer, we detected the expression of ISL1 in human breast carcinoma cells, MDA-MB-231 and MCF-7, and in human normal breast tissue cells. MCF-10A was used as control. As shown in Figure 1A and B, both the protein and mRNA levels of ISL1 were significantly upregulated in MDA-MB-231 and MCF-7 cells (Figure 1A and B). Next, in order to determine the expression of ISL1 in breast cancer patients, we collected 108 pairs of breast cancer tissue samples and adjacent normal tissue samples. The mRNA and protein levels of ISL1 were detected by qRT-PCR and Western blotting, respectively. The results suggested that ISL1 was upregulated in the tumor tissue samples (Figure 1C and D). Moreover, we found that a high expression of ISL1 was corrected with pathological grade, tumor size, and metastasis, but there are no association between ISL expression and age, differentiation (Table 1). Moreover, we analyzed the expression of ISL1 on the bioinformatics analysis website (http://www.cbioportal.org), and the result indicated that ISL1 amplified in breast cancer (Figure 1E). Next, we analyzed the correlation of ISL expression and the survival curve of breast cancer patients. The results revealed that the high expression of ISL1 predicted a poor prognosis $(P=0.035$, Figure $1 \mathrm{~F})$.

\section{ISLI facilitates proliferation of breast cancer cells}

Because of the correlation between ISL1 expression and tumor size, we assumed that ISL1 might promote breast cancer cell proliferation. In order to verify our hypothesis, we performed colony formation analysis and CCK-8 analysis to analyze the effect of ISL1 on cell proliferation. ISL1 was overexpressed or knocked down in MCF-7 cells. The expression of ISL1 was detected by qRT-PCR and Western blotting, respectively (Figure 2A and B). The results of colony formation analysis suggested that ectopic expression of ISL1 strongly improved the number of colonies; however, inhibition of ISL1 obviously decreased the number of colonies (Figure 2C). In addition, CCK-8 analysis was performed every 12 hours, and the absorbance of OD $450 \mathrm{~nm}$ indicated the number of surviving cells. As shown in Figure 2D, overexpression of ISL1 significantly increased the proliferation rate of cells compared with vector group (Figure 2D). However, inhibition of ISL1 inhibited the proliferation rate of cells compared with SCR group (Figure 2D). To sum up, our work reveals that ISL1 plays an important role in cell proliferation.

\section{ISLI correlates with VEGF expression in MCF-7 cells}

A previous study has found that the expression of ISL1 was correlated with VEGF expression. ${ }^{10}$ To further explore the function of ISL1 in breast cancer, we also detected the 


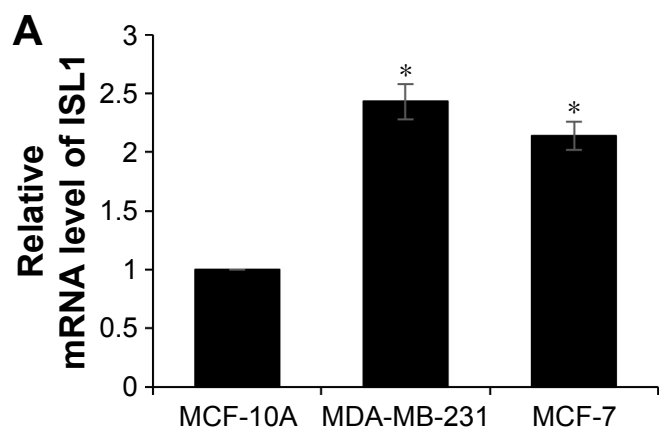

B
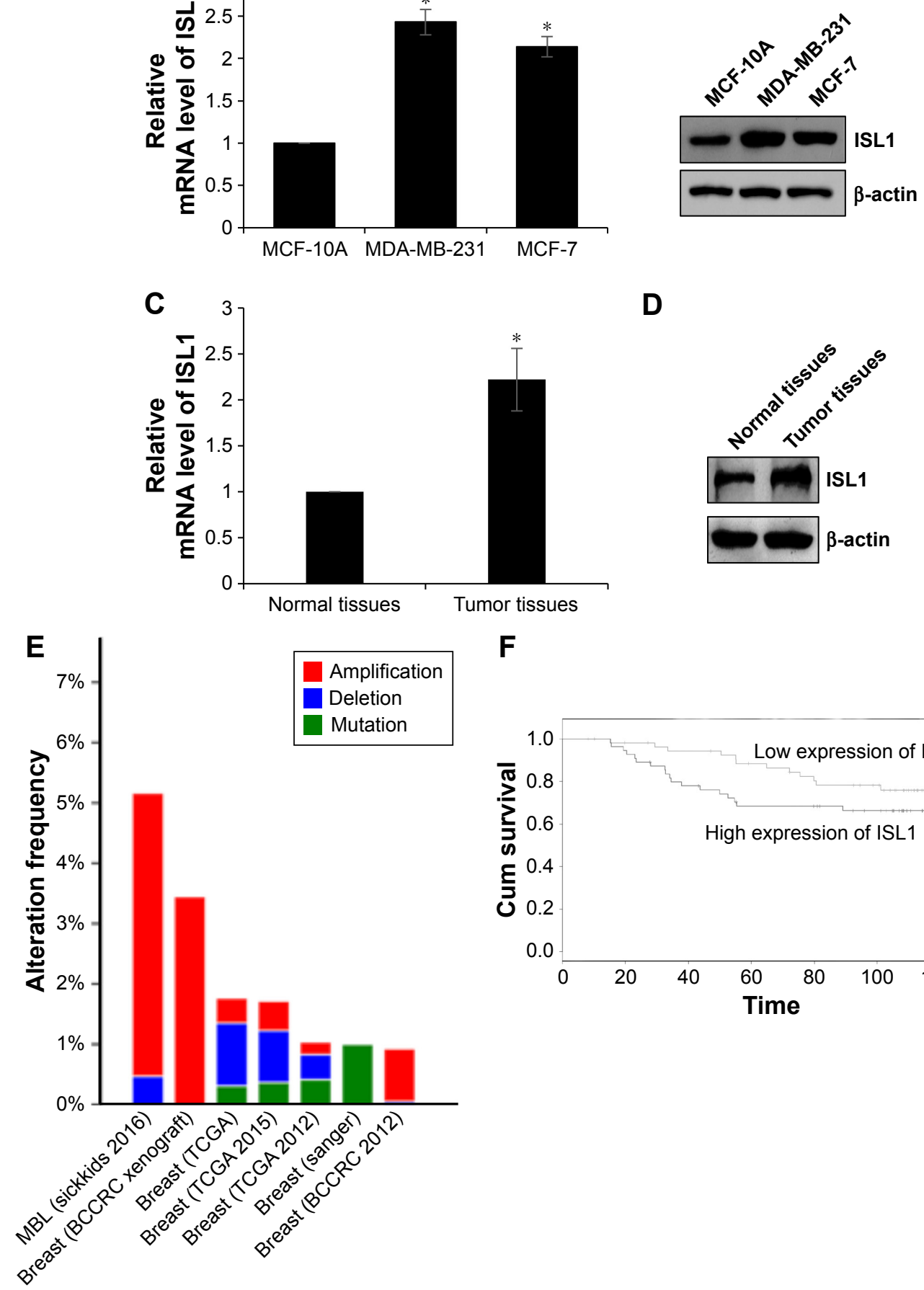

$\mathbf{F}$

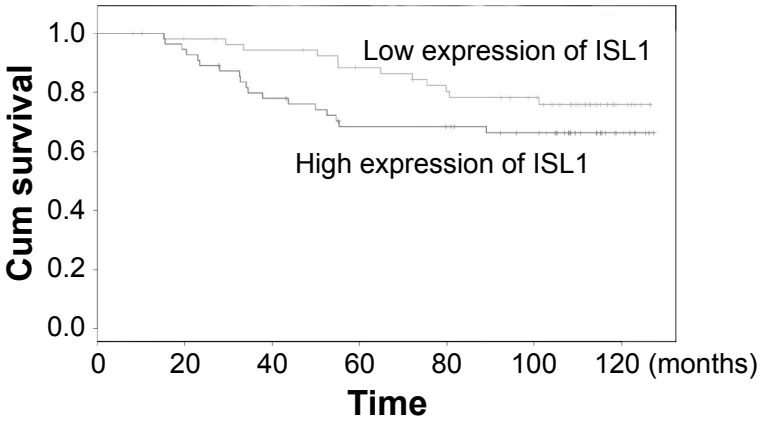

Figure I ISLI is upregulated in breast cancer, and the expression of ISLI is corrected with tumor size and metastasis.

Notes: (A) The mRNA level of ISLI in MDA-MB-23I and MCF-7 cells was determined by qRT-PCR; MCF-IOA was used as the control group. ${ }^{*} p<0.05$, MDA-MB-23I or MCF-7 vs MCF-IOA. (B) The protein level of ISLI in MDA-MB-23I and MCF-7 cells was determined by Western blotting; MCF-IOA was used as the control group. (C) The protein level of ISLI in breast cancer tissue samples was determined by Western blotting; adjacent normal tissue samples were used as the control group. ${ }^{*} p<0.05$, tumor tissues vs normal tissues. (D) The mRNA level of ISLI in breast cancer tissue samples was determined by qRT-PCR; adjacent normal tissue samples were used as the control group. (E) The expression of ISLI in breast cancer was assessed on a website (http://www.cbioportal.org). MBL (sickkids 2016): Mutational profiles of metastatic breast cancer (France, 2016). (F) The survival curve in 108 breast cancer patients according to ISLI expression was analyzed by the Kaplan-Meier method.

Abbreviations: Cum, cumulative; qRT-PCR, quantitative real-time polymerase chain reaction.

correction between ISL1 and VEGF. We overexpressed or knocked down ISL1 in MCF-7 cells and detected the protein and mRNA levels of VEGF by qRT-PCR and Western blotting, respectively. As shown in Figure $3 \mathrm{~A}$ and $\mathrm{B}$, the
mRNA level and the protein level of VEGF were regulated by ISL1. Ectopic expression of ISL1 promoted the expression of VEGF; however, inhibition of ISL1 suppressed the expression of VEGF (Figure 3A and B). 
Table I Clinicopathologic variables in 108 breast cancer patients

\begin{tabular}{|c|c|c|c|c|}
\hline \multirow[t]{2}{*}{ Variables } & \multirow[t]{2}{*}{$\begin{array}{l}\text { Patients } \\
(n=108)\end{array}$} & \multicolumn{2}{|c|}{$\begin{array}{l}\text { ISLI protein } \\
\text { expression }\end{array}$} & \multirow[t]{2}{*}{$P$-value } \\
\hline & & $\begin{array}{l}\text { Low } \\
(n=42)\end{array}$ & $\begin{array}{l}\text { High } \\
(n=66)\end{array}$ & \\
\hline \multicolumn{4}{|l|}{ Age (years) } & 0.982 \\
\hline$<40$ & 59 & 23 & 36 & \\
\hline$\geq 40$ & 49 & 19 & 30 & \\
\hline \multicolumn{4}{|c|}{ Tumor size (diameter) } & $<0.001$ \\
\hline Small $(\leq 3 \mathrm{~cm})$ & 54 & 30 & 24 & \\
\hline Large $(\geq 3 \mathrm{~cm})$ & 54 & 12 & 42 & \\
\hline \multicolumn{4}{|l|}{ Pathological grade } & 0.007 \\
\hline I-II & 47 & 25 & 22 & \\
\hline III-IV & 61 & 17 & 44 & \\
\hline \multicolumn{4}{|l|}{ PT status } & $<0.001$ \\
\hline pTI & 48 & 30 & 18 & \\
\hline PT2-4 & 60 & 12 & 48 & \\
\hline \multicolumn{4}{|l|}{$\mathrm{pN}$ status } & 0.018 \\
\hline pNO & 44 & 23 & 21 & \\
\hline $\mathrm{pNI}-2$ & 64 & 19 & 45 & \\
\hline \multicolumn{4}{|l|}{ Metastasis } & 0.041 \\
\hline Yes & 57 & 17 & 40 & \\
\hline No & 51 & 25 & 26 & \\
\hline \multicolumn{4}{|l|}{ Differentiation } & 0.059 \\
\hline Well/moderate & 52 & 25 & 27 & \\
\hline Poor & 56 & 17 & 39 & \\
\hline
\end{tabular}

\section{Downregulation of ISLI suppresses angiogenesis in breast cancer}

VEGF plays a key role in angiogenesis, and so, we detected the function of ISL1 on angiogenesis in breast cancer. HUVECs were incubated with conditional media (CM) from MCF-7 cells which were treated with vector, ISL1 or SCR, and siISL1. After incubation for 24 hours, the number of tubes was counted under a light microscope. The capillary-like areas and network structures were separately analyzed using Image $\mathrm{J}$ software. The relative capillary-like structure density was measured, and the number of capillary-like areas of the control group was used as $100 \%$. As shown in Figure $4 \mathrm{~A}$ and B, after transfection with siISL1, the number of tubes was obviously lower than that of the SCR group (Figure 4A and B). While ISL1 was overexpressed, the number of tubes was obviously higher than that of the vector group (Figure 4A and B). Taken together, our work suggests that ISL1 facilitates angiogenesis in breast cancer.

\section{ISLI facilitates breast cancer cells migration and invasion}

Our previous work revealed that the expression of ISL1 was also correlated with metastasis. So, we detected the effect of ISL1 on cell migration and invasion by wound healing and transwell invasion assays. MDA-MB-231 cells were transfected with vector, ISL1 or SCR, and siISL1, and the expression of ISL1 was detected by qRT-PCR and Western blotting (Figure 5A and B). The results of wound healing assay demonstrated that the siISL1 decreased inclosure of cells compared with the SCR group $(P<0.05)$; however, ectopic expression of ISL1 increased the inclosure of cells, indicating a role for ISL1 in the migration of breast cancer cells (Figure 5C). Subsequently, in order to substantiate this observation, we performed a transwell invasion assay to determine the role of ISL1 on invasion of MDA-MB-231 cells. As shown in Figure 5D, ectopic expression of ISL1 increased the number of invaded cells compared with the control group, and ISL1 inhibition decreased the number of invaded cells (Figure 5D). Together, these results show that ISL1 facilitates breast cancer cells migration and invasion.

\section{ISLI promotes MRI Phenotyping detection}

Since ISL1 facilitated angiogenesis in breast cancer, subsequently, we also performed MRI assay. The results suggested that the permeability-surface area product was obviously higher in ISL1-overexpressed group than that in the vector group; however, the permeability-surface area product was almost undetectable when ISL1 was knocked down (Figure 6).

\section{Discussion}

ISL1 has been found to play key roles in various organs and tissues. ${ }^{17,18}$ The expression of ISL1 is closely related to the occurrence and progression of various tumors. Moreover, ISL1 expression is high in several cancers, including pheochromocytoma, ${ }^{19}$ gastrointestinal, pancreatic and lung tumors, ${ }^{20}$ and bile duct carcinoma. ${ }^{21}$ These studies suggested the relationship between tumorigenesis and ISL1. Recently, ISL1 has been reported to promote angiogenesis in HUVECs through regulating VEGF. ${ }^{10}$ Although a previous report indicated that ISL1 was downregulated in breast cancer, ${ }^{22}$ further details about the function of ISL1 in breast cancer remain unknown. In order to explore the function of ISL1 in breast cancer, we determined the expression of ISL1 in breast cancer cell lines and tissue sample compared with human normal breast cell lines and adjacent normal tissue samples, respectively. To our surprise, we found that ISL1 was upregulated in breast cancer, which was contrary to previous findings; the different results might be due to an antibody or some difference in the way in which the experiment was conducted. 


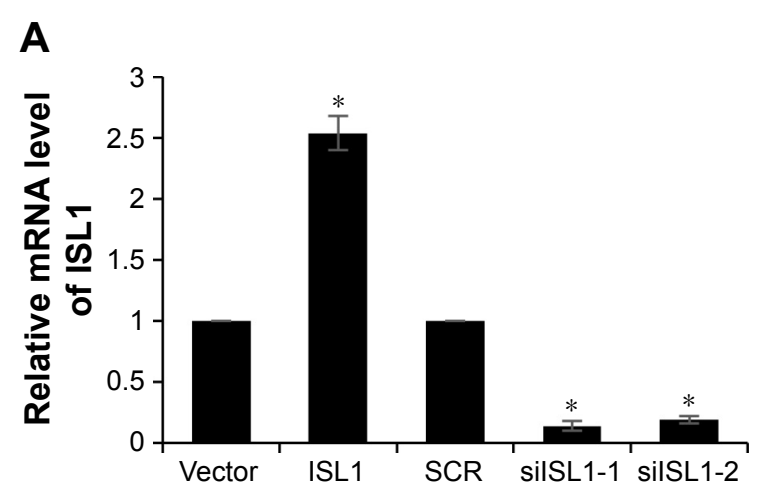

B

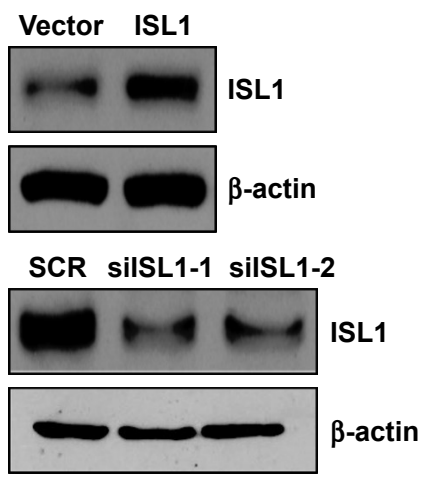

C
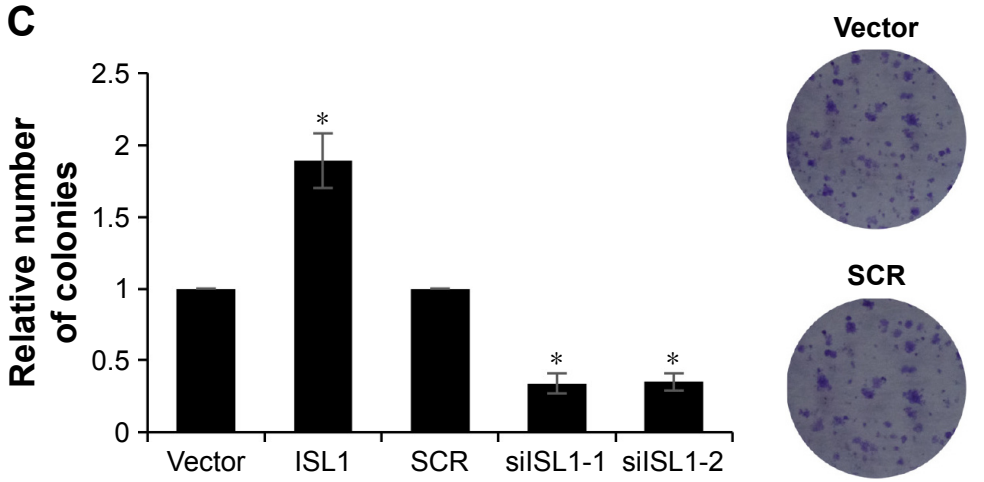

ISL1

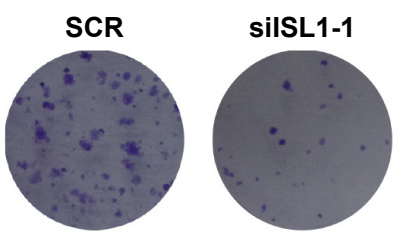

silSL1-2

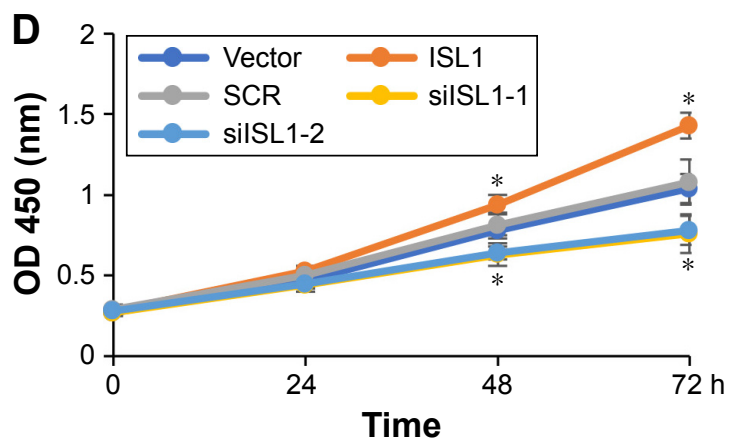

Figure 2 ISLI facilitates proliferation of breast cancer cells.

Notes: (A) MCF-7 cells were treated with vector, ISLI or SCR, ISLI siRNA (silSLI), respectively. The mRNA level of ISLI was detected by qRT-PCR. (B) ISLI was overexpressed or knocked down in MCF-7 cells; the protein level of ISLI was detected by Western blotting. (C) ISLI was overexpressed or knocked down in MCF-7 cells; the colony formation analysis was performed to detect the effect of ISLI on cell proliferation. The graph indicated the relative number of colonies. (D) ISLI was overexpressed or knocked down in MCF-7 cells; the CCK-8 assay was performed to assess the proliferation ability of MCF-7 affected by ISLI. *p $<0.05$, ISLI vs vector, silSLI vs SCR. Abbreviations: OD, optical density; qRT-PCR, quantitative real-time polymerase chain reaction; SCR, scramble siRNA.

A

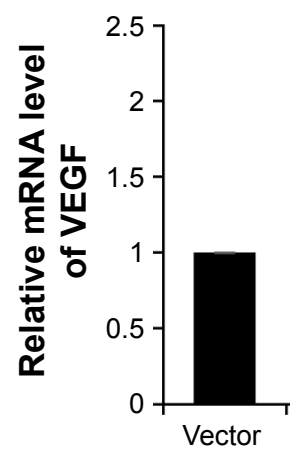

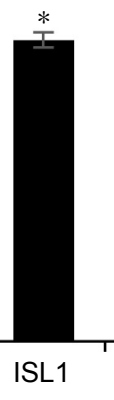

ISL1

\section{B}

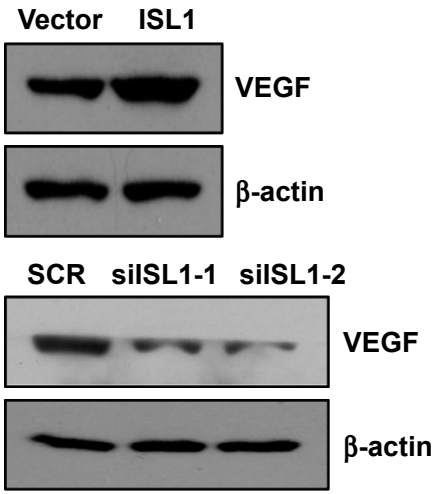

Figure 3 ISLI correlates with VEGF expression in MCF-7 cells.

Notes: (A) MCF-7 cells were treated with vector, ISLI or SCR, ISLI siRNA (silSLI), respectively. The mRNA level of VEGF was detected by qRT-PCR. *p<0.05, ISLI vs vector, silSLI vs SCR. (B) ISLI was overexpressed or knocked down in MCF-7 cells; the protein level of VEGF was detected by Western blotting. Abbreviations: qRT-PCR, quantitative real-time polymerase chain reaction; SCR, scramble siRNA; VEGF, vascular endothelial growth factor. 

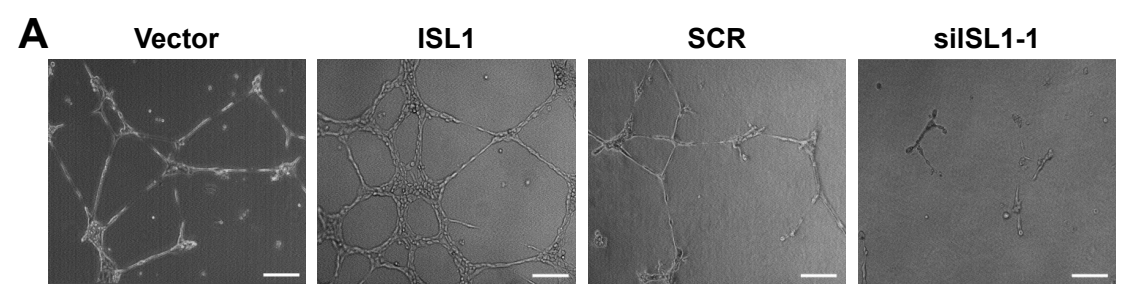

silSL1-2

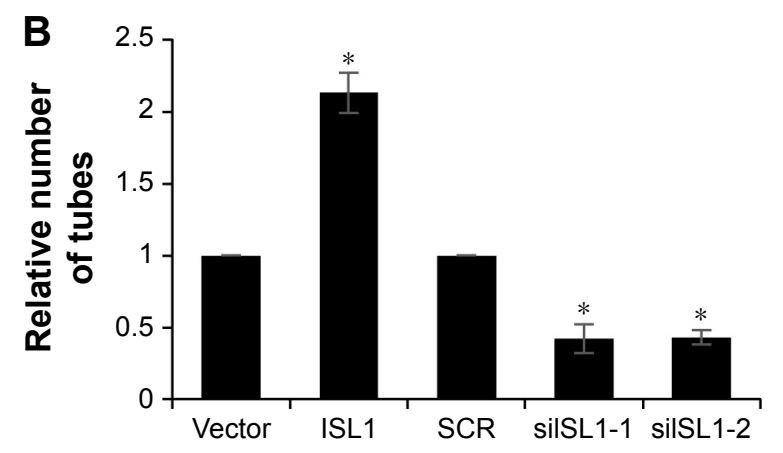

Figure 4 Downregulation of ISLI suppresses angiogenesis in breast cancer.

Notes: (A) MCF-7 cells were treated with vector, ISLI or SCR, ISLI siRNA (silSLI), respectively. After transfection for $48 \mathrm{~h}$, the HUVECs were incubated with conditional media (CM) from MCF-7 cells. The number of tubes formed indicates the effect of ISLI on angiogenesis. Magnification: 40x, scale bars $=250 \mu \mathrm{m}$. (B) The graph indicates the relative number of tubes. ${ }^{p}<<0.05$, ISLI vs vector, silSLI vs SCR.

Abbreviations: HUVECs, human umbilical vein endothelial cells; SCR, scramble siRNA.

A
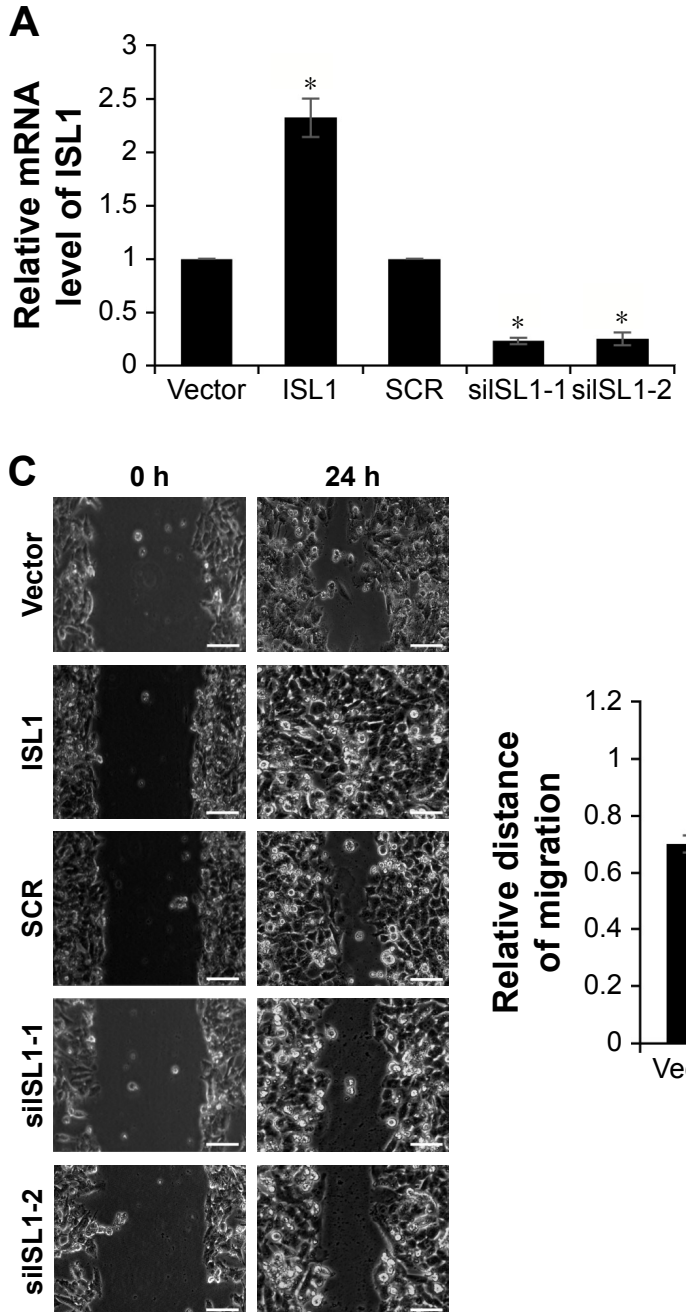

B Vector ISL1

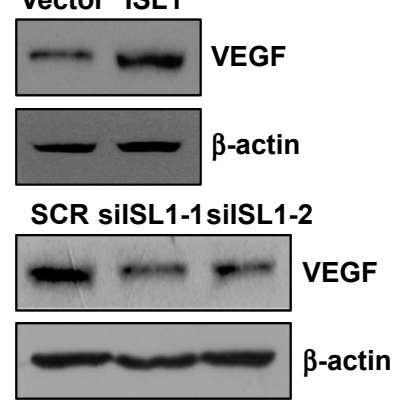

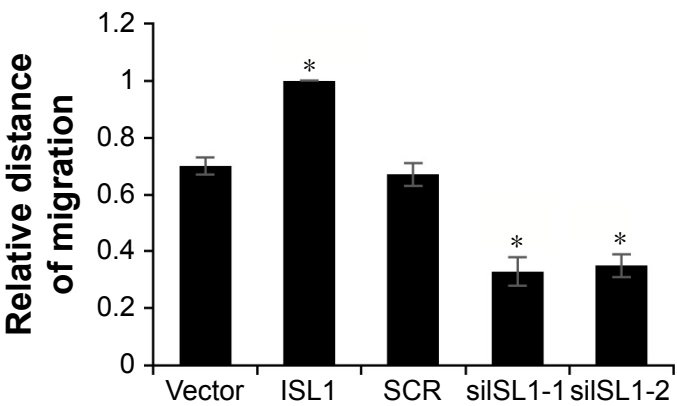

Figure 5 (Continued) 
D

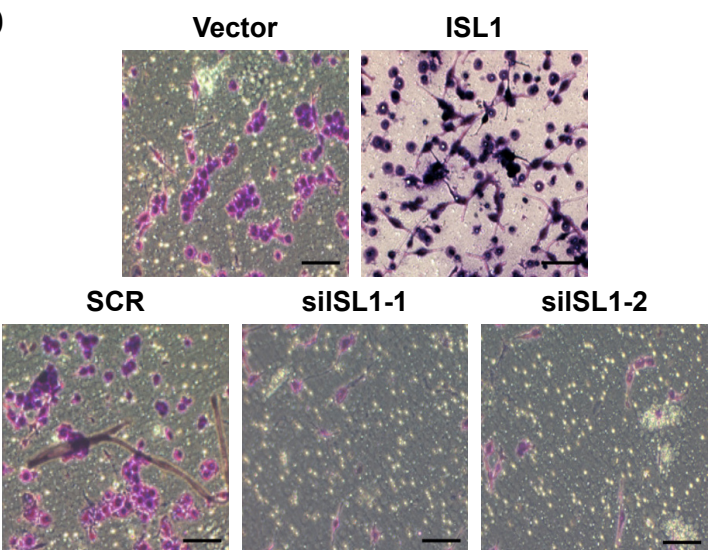

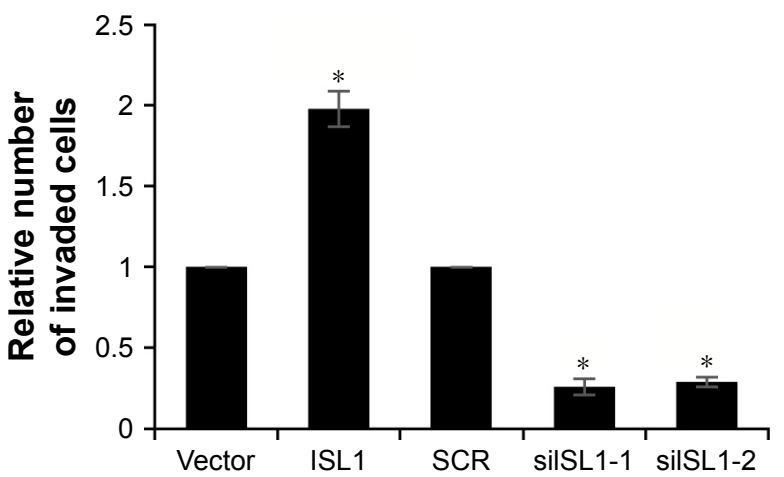

Figure 5 ISLI facilitates breast cancer cells migration and invasion.

Notes: (A) MDA-MB-23I cells were treated with vector, ISLI or SCR, ISLI siRNA (silSLI), respectively. The mRNA level of VEGF was detected by qRT-PCR. (B) ISLI was overexpressed or knocked down in MDA-MB-23I cells; the protein level of VEGF was detected by Western blotting. (C) Wound healing analysis was used to detect the role of ISLI in cell migration. ISLI was overexpressed or knocked down in MDA-MB-23 I cells. The graph indicates the relative distance of migration. Scale bars $=200 \mu$ m; ${ }^{*} p<0.05$, ISLI vs vector, silSLI vs SCR. (D) Transwell invasion analysis was used to detect the role of ISLI in cell invasion. ISLI was overexpressed or knocked down in MDA-MB-23 I cells. The graph indicates the relative number of invaded cells. Magnification: $20 \times$, scale bars $=200 \mu \mathrm{m}$. $* p<0.05$, ISLI vs vector, silSLI vs SCR.

Abbreviations: qRT-PCR, quantitative real-time polymerase chain reaction; SCR, scramble siRNA; VEGF, vascular endothelial growth factor.

In addition, the bioinformatics analysis also revealed that ISL1 was amplified in breast cancer. Moreover, the high expression of ISL1 was positively associated with tumor size and metastasis, suggesting that ISL1 played a key role in cell proliferation and metastasis. Previous work showed that ISL1 suppressed cell proliferation in cancer stem cells, but our work revealed that ISL1 promoted cell proliferation in breast cancer cells.

To further investigate the underlying mechanism, we cultured HUVECs with CM from MCF-7 cells that were transfected with vector, ISL1 or SCR, and siISL1 and detected the tube formation in vitro. We found that ISL1 inhibition obviously downregulated the expression of VEGF and decreased tube formation of the vascular endothelial cells. However, ectopic expression of ISL1 significantly

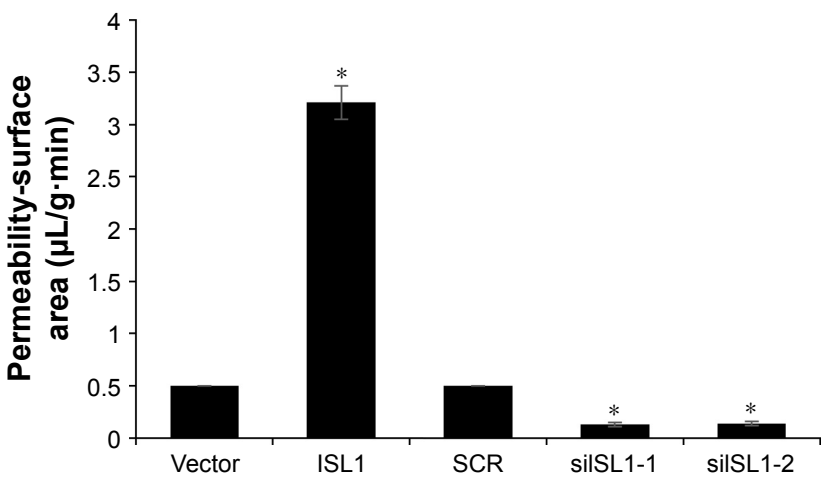

Figure 6 ISLI promotes MRI phenotyping detection.

Note: MCF-7 vector and MCF-7 ISLI overexpression tumor-bearing mice, or MCF-7 SCR and MCF-7 shISLI tumor-bearing mice were utilized to compare functional MRI maps of the permeability-surface area product. $*_{p}<0.05$, ISLI vs vector, silSLI vs SCR.

Abbreviation: SCR, scramble siRNA. upregulated the expression of VEGF and increased tube formation of the vascular endothelial cells.

In summary, our work suggests that the expression of ISL1 is high in breast cancer, and its expression is associated with tumor size, metastasis, and poor prognosis. Moreover, inhibition of endogenous ISL1 expression suppresses the breast cancer cell proliferation, migration, and invasion. In addition, ISL1 regulates angiogenesis in breast cancer. The function of ISL1 in promoting angiogenesis is related to VEGF expression. Therefore, this study reveals that ISL1 regulates the process of angiogenesis accompanied by VEGF, thereby supplying nutrition for cancer cells, and promoting cell proliferation and metastasis.

\section{Disclosure}

The authors report no conflicts of interest in this work.

\section{References}

1. Siegel RL, Miller KD, Jemal A. Cancer statistics, 2016. CA Cancer J Clin. 2016;66(1):7-30.

2. Carlson RW, Allred DC, Anderson BO, et al. Breast cancer. Clinical practice guidelines in oncology. $J$ Natl Compr Canc Netw. 2009;7(2): 122-192.

3. da Costa Vieira RA, Biller G, Uemura G, Ruiz CA, Curado MP. Breast cancer screening in developing countries. Clinics. 2017;72(4): 244-253.

4. Karlsson O, Thor S, Norberg T, Ohlsson H, Edlund T. Insulin gene enhancer binding protein Isl-1 is a member of a novel class of proteins containing both a homeo- and a Cys-His domain. Nature. 1990; 344(6269):879-882.

5. Hobert O, Westphal H. Functions of LIM-homeobox genes. Trends Genet. 2000;16(2):75-83.

6. Bejarano-Escobar R, Alvarez-Hernan G, Morona R, Gonzalez A, Martin-Partido G, Francisco-Morcillo J. Expression and function of the LIM-homeodomain transcription factor Islet-1 in the developing and mature vertebrate retina. Exp Eye Res. 2015;138:22-31. 
7. Erlenbach-Wunsch K, Haller F, Taubert H, Wurl P, Hartmann A, Agaimy A. Expression of the LIM homeobox domain transcription factor ISL1 (Islet-1) is frequent in rhabdomyosarcoma but very limited in other soft tissue sarcoma types. Pathology. 2014;46(4):289-295.

8. Shi Q, Wang W, Jia Z, Chen P, Ma K, Zhou C. ISL1, a novel regulator of $\mathrm{CCNB} 1, \mathrm{CCNB} 2$ and c-MYC genes, promotes gastric cancer cell proliferation and tumor growth. Oncotarget. 2016;7(24): 36489-36500.

9. Wang X, He C, Hu X. LIM homeobox transcription factors, a novel subfamily which plays an important role in cancer (review). Oncology Rep. 2014;31(5):1975-1985.

10. Xiong SQ, Jiang HB, Li YX, et al. Role of endogenous insulin gene enhancer protein ISL-1 in angiogenesis. Mol Vision. 2016;22: 1375-1386.

11. Pe'er J, Shweiki D, Itin A, Hemo I, Gnessin H, Keshet E. Hypoxiainduced expression of vascular endothelial growth factor by retinal cells is a common factor in neovascularizing ocular diseases. Lab Invest. 1995;72(6):638-645.

12. Selle F, Emile G, Pautier P, et al. Safety of bevacizumab in clinical practice for recurrent ovarian cancer: a retrospective cohort study. Oncol Lett. 2016;11(3):1859-1865.

13. Gonzalez VH, Giuliari GP, Banda RM, Guel DA. Intravitreal injection of pegaptanib sodium for proliferative diabetic retinopathy. $\mathrm{Br} J$ Ophthalmol. 2009;93(11):1474-1478.

14. Rothenbuehler SP, Waeber D, Brinkmann CK, Wolf S, WolfSchnurrbusch UE. Effects of ranibizumab in patients with subfoveal choroidal neovascularization attributable to age-related macular degeneration. Am J Ophthalmol. 2009;147(5):831-837.
15. Avery RL, Pearlman J, Pieramici DJ, et al. Intravitreal bevacizumab (Avastin) in the treatment of proliferative diabetic retinopathy. Ophthalmology. 2006;113(10):1695.e1-e15.

16. Sun T, Wang H, Li Q, Qian Z, Shen C. Forkhead box protein k1 recruits TET1 to act as a tumor suppressor and is associated with MRI detection. Jpn J Clin Oncol. 2016;46(3):209-221.

17. Pfaff SL, Mendelsohn M, Stewart CL, Edlund T, Jessell TM. Requirement for LIM homeobox gene Is11 in motor neuron generation reveals a motor neuron-dependent step in interneuron differentiation. Cell. 1996;84(2):309-320.

18. Du A, Hunter CS, Murray J, et al. Islet-1 is required for the maturation, proliferation, and survival of the endocrine pancreas. Diabetes. 2009; 58(9):2059-2069.

19. Hattori Y, Kanamoto N, Kawano K, et al. Molecular characterization of tumors from a transgenic mouse adrenal tumor model: comparison with human pheochromocytoma. Int J Oncol. 2010;37(3):695-705.

20. Schmitt AM, Riniker F, Anlauf M, et al. Islet 1 (Isl1) expression is a reliable marker for pancreatic endocrine tumors and their metastases. Am J Surg Pathol. 2008;32(3):420-425.

21. Hansel DE, Rahman A, Hidalgo M, et al. Identification of novel cellular targets in biliary tract cancers using global gene expression technology. Am J Pathol. 2003;163(1):217-229.

22. Pathania R, Ramachandran S, Elangovan S, et al. DNMT1 is essential for mammary and cancer stem cell maintenance and tumorigenesis. Nat Commun. 2015;6:6910.
OncoTargets and Therapy

\section{Publish your work in this journal}

OncoTargets and Therapy is an international, peer-reviewed, open access journal focusing on the pathological basis of all cancers, potential targets for therapy and treatment protocols employed to improve the management of cancer patients. The journal also focuses on the impact of management programs and new therapeutic agents and protocols on

\section{Dovepress}

patient perspectives such as quality of life, adherence and satisfaction. The manuscript management system is completely online and includes a very quick and fair peer-review system, which is all easy to use. Visit http://www.dovepress.com/testimonials.php to read real quotes from published authors. 